\title{
Desafios ético-políticos no exercício da cidadania científica em Comunicação
}

\author{
Ethical-political challenges in the exercise of scientific citizenship in Communication \\ Desafíos ético-políticos en el ejercicio de la ciudadanía científica en Comunicación
}

DOI: https://doi.org/10.1590/1809-58442021309

\author{
Alberto Efendy Maldonado ${ }^{1}$ \\ https://orcid.org/0000-0002-5704-4544
}

${ }^{1}$ (Universidade do Vale do Rio dos Sinos, Escola da Indústria Criativa, Programa de Pós-Graduação em Comunicação. São Leopoldo - RS, Brasil).

\section{Resumo}

O artigo apresenta uma reflexão transmetodológica sobre a experiência de construção de redes de solidariedade acadêmica, para o exercício de uma cidadania científica crítica, experimental, inventiva e propositiva. Contextualiza a realidade econômico-política e acadêmica latino-americana, e os obstáculos que para a produção de pesquisa e conhecimento transformador tem de enfrentar, em institucionalidades condicionadas pelo modelo positivista de ciência. Argumenta sobre a necessidade da construção de poderes comunieducativos que assumam o compromisso ético/político de propor alternativas para superar o neocolonialismo acadêmico e os modos burocráticos de exercício investigativo. Trabalha uma perspectiva teórico-metodológica heurística, em cooperação com o pensamento crítico latino-americano e mundial.

Palavras-chave: Cidadania científica. Transmetodologia. Redes acadêmicas. Pesquisa crítica. América Latina.

\begin{abstract}
The article presents a transmethodological reflection on the experience of building academic solidarity networks, for the exercise of critical scientific citizenship, experimental, inventive and propositional. Contextualizes Latin American economic-political and academic reality, and the obstacles that for research production and transformative knowledge have to face, in institutions conditioned by the positivist model of science. Argues about the need to build community powers that assume the ethical / political commitment to propose alternatives to overcome academic neocolonialism, and bureaucratic modes of investigative exercise. Works on a heuristic theoretical-methodological perspective, in cooperation with Latin American and world critical thinking.
\end{abstract}

Keywords: Scientific citizenship. Transmethodology. Academic networks. Critical research. Latin America. 


\section{Resumen}

El artículo presenta una reflexión transmetodológica sobre la experiencia de construcción de redes de solidaridad académica, para el ejercicio de una ciudadanía científica crítica, experimental, inventiva y propositiva. Contextualiza la realidad económico-política y académica latinoamericana, y los obstáculos que para la producción de investigación y conocimiento transformador tiene que enfrentar, en institucionalidades condicionadas por el modelo positivista de ciencia. Argumenta acerca de la necesidad de construir poderes comunieducativos que asuman el compromiso ético/ político de proponer alternativas para superar el neocolonialismo académico, y los modos burocráticos de ejercicio investigativo. Trabaja una perspectiva teórico-metodológica heurística, en cooperación con el pensamiento crítico latinoamericano y mundial.

Palabras clave: Ciudadanía científica. Transmetodología. Redes académicas. Investigación crítica. América Latina.

\section{Necessidade de grupos, núcleos, coletivos, equipes e instituições para o exercício da cidadania científica: a experiência da Rede AMLAT}

A necessidade de produção coletiva de conhecimento levou-nos a organizar a partir de agosto de 2002 o Grupo de Pesquisa Processos Comunicacionais: epistemologia, midiatização e recepção (PROCESSOCOM), que definiu como eixos transmetodológicos da sua constituição e de sua operação investigativa as seguintes categorias: epistemologia, midiatização, mediações e recepção. Essa articulação, pouco comum, em uma realidade institucional e ministerial impregnada pelo paradigma positivista, estabeleceu um arranjo de complexidade que definiu a epistemologia como uma dimensão abrangente e necessária, para o conjunto de dimensões necessárias nos processos de produção de conhecimento (MALDONADO, 2019a, 2019b). Assim, a epistemologia mantém seu caráter gnosiológico, filosófico, (meta)metodológico, (meta)teórico, (meta)científico; entretanto amplia-se, no exercício analítico crítico reflexivo, de uma práxis que atravessa todas as dimensões da pesquisa, da mais operativa (técnica) à mais complexa (meta)científica (filosófica/lógica; sociologia da ciência, história da ciência, psicologia da ciência, antropologia da ciência, comunicologia da ciência). Essa definição sintetizou aprendizados realizados durante trinta anos de trabalho intelectual e investigativo, entre os quais se destacou, no contexto brasileiro, o trabalho de investigação multimetodológico coordenado por Immacolata Lopes e Maria Aparecida Baccega na Universidade de São Paulo (USP), que se configurou como um contexto acadêmico suscitador para a posterior configuração da vertente transmetodológica, no contexto do Programa de Pós-Graduação em Ciências da Comunicação da Universidade do Vale do Rio dos Sinos (PGCC-UNISINOS) (BONIN, 2011; BONIN; ROSÁRIO, 2013).

Essa articulação de investigadoras e investigadores gerou e potencializou a produção de pesquisas críticas renovadoras, experimentais, problematizadoras dos processos midiáticos e dos processos comunicacionais, nas duas primeiras décadas do século XXI. As premissas filosóficas, os postulados, as estratégias investigativas, as propostas ético/políticas, os 
argumentos, as orientações de procedimentos; em síntese, a construção e produção concreta de investigações, articuladas sob a perspectiva transmetodológica, concretizou hipóteses e as transformou em teses, dissertações, livros, artigos, relatórios e produções intelectuais que expressam a consistência, a fecundidade e a inventividade de um coletivo de investigação que configurou um grupo radical, para gerar uma cultura acadêmica solidária e transformadora, como exercício concreto de cidadania científica, como agir existencial emancipatório, e como compromisso ético/político estratégico com a vida, a humanidade e o bem-viver.

Com efeito, a partir de 2009, e com fomento do Conselho Nacional de Desenvolvimento Científico e Tecnológico (CNPq), organiza-se a Rede Temática de Cooperação Científica: Comunicação, Cidadania, Educação e Integração na América Latina (Rede AMLAT) como um complexo de cooperação focado na pesquisa, no estudo, no debate e na produção de metodologias transformadoras; na perspectiva da confluência e da confrontação metodológica em investigação crítica. O objetivo geral foi estabelecer uma rede de cooperação acadêmica internacional, que possibilitasse o compartilhamento contínuo de experiências de investigação; de problematizações epistemológicas; de produção teórica e desenho de procedimentos investigativos críticos. Esse objetivo foi sendo construído de maneira sistemática mediante o desenho de uma programação semestral articulada, que incluiu seminários, encontros, conferências, cursos intensivos, aulas compartilhadas, avaliação de teses e dissertações, projetos integrados, produção de livros e dossiês, atividades artísticas e culturais conjuntas; como também, o estabelecimento de laços afetivos/existenciais, na perspectiva da construção de outros mundos possíveis.

Todo esse esforço organizativo, se articulou, e se articula, no sentido de contribuir para o fortalecimento de um campo científico em Ciências da Comunicação na América Latina, que se constitua em um referente estratégico para a produção crítica de conhecimento na área, e marque uma ruptura estratégica radical com os setores utilitaristas, instrumentalistas, funcionalistas, positivistas e conservadores no campo das Ciências da Comunicação. Esses setores são agentes importantes na manutenção do status neocolonial, sob a hegemonia do paradigma positivista estadunidense, e condicionam fortemente a vida acadêmica latino-americana.

De fato, a Rede AMLAT tem constituído uma comunidade heterotópica e uma cultura investigativa crítica, que oferece para as/os estudantes, para os professores(as), para as/os investigadores e para as comunidades nas quais atua produções suscitadoras de saberes alternativos, de produção de pesquisa experimental inventiva, de articulação colaborativa horizontal - não hierarquizada. Ao mesmo tempo, rejeita as subordinações, promove a diversidade de iniciativas de investigação transformadora, como caminho de formação consistente de investigadoras(es), pensadoras(es), e cidadãs e cidadãos comprometidas(os) com o bem-comum, a justiça, a verdade multifacetada, a liberdade individual e coletiva, a fraternidade científica, e a luta por uma vida digna para o conjunto da humanidade.

As(os) trabalhadoras(es) intelectuais, os artesãos e artesãs da investigação, e as cientistas e os cientistas partícipes na Rede AMLAT têm produzido um conjunto relevante 
de teses, dissertações, livros, artigos, capítulos, ensaios, relatórios e projetos ${ }^{1}$ sobre cidadania comunicacional; educomunicação; processos comunicacionais nas migrações; musicalidades transmetodológicas; processos comunicacionais dos povos originários; crítica sistemática dos formatos e gêneros midiáticos corporativos; meios de comunicação comunitários e alternativos; comunicação digital alternativa; análise crítica da produção e dos discursos midiáticos; processos de inter-relação receptiva entre públicos e mídias; análise sociocultural/audiovisual da publicidade; processos educomunicativos para a saúde comunitária; midiatização dos processos políticos; comunicação comunitária; processos comunicacionais de coletivos e pessoas com deficiências; processos comunicacionais de travestis; comunicação comunitária; crítica sistemática dos sistemas midiáticos hegemônicos; corporalidades; cartografias comunicacionais; territorialidades discursivas midiáticas; análise econômica-política dos sistemas de controle, vigilância e desinformação (PADILLA; MALDONADO, 2009; MALDONADO; PEREIRA, 2010; MALDONADO; BARRETO; LACERDA, 2011; MALDONADO et al., 2012; PADILLA; MALDONADO; GAMBOA, 2015; RIFIOTIS et al., 2011).

Nesses processos, o exercício da cidadania científica é fator estratégico imprescindível para as transformações socioculturais e econômicas dos países latino-americanos; lamentavelmente, esse componente necessário dos planos, projetos, programas, propostas e políticas educativas está pouco atendido, pouco problematizado, pouco compreendido; e muitas vezes obliterado pela ação sistemática de poderes institucionais, ministeriais e de lobbys, que têm interesse por manter o campo científico como subserviente das grandes empresas transnacionais, e das empresas das elites oligárquicas regionais. Nesses processos de restrição, as tecnoburocracias latino-americanas reduzem o fazer científico à tecnociência produtivista, funcionalizada para a maximização e para a concentração dos lucros em um ínfimo setor da população.

Nessa realidade atuam as megaempresas extrativistas (petróleo, lítio, cobre, ferro, diamantes, etc.); as transnacionais farmacêuticas (concentradoras de patentes, e formuladoras de impedimentos jurídicos para restringir a pesquisa livre e inventiva na área da saúde); o sistema financeiro internacional (verdadeiro complexo de agiotas internacionais sem nenhuma responsabilidade social); o circuito comercial do mercado de matérias primas (commodities), em especial de produtos agropecuários, dos quais América Latina é forte provedora mundial. Nessa realidade hegemônica, atuam decisivamente as holdings de mídia e de telecomunicações (Globo, Televisa, TELCET, América Móvel, TIM, Telefônica, Telecom etc.), que se situam em um lugar central na articulação do poder do capital, dado que a informação e a comunicação são setores estratégicos imprescindíveis para o funcionamento do sistema econômico capitalista, no atual modelo informático/cognitivo. Esses sistemas multimidiáticos funcionam como sistemas de produção simbólica estratégica para o

1 Premiados pela Coordenação de Aperfeiçoamento de Pessoal de Nível Superior (Capes), o CNPq, a Sociedade Brasileira de Estudos Interdisciplinares da Comunicação (INTERCOM), a Associação Nacional dos Programas de Pós-Graduação em Comunicação (COMPÓS), a Organização das Nações Unidas para a Educação, a Ciência e a Cultura (UNESCO), e a UNISINOS. 
condicionamento, a vigilância e o controle das(dos) consumidoras(es) (ASSANGE, 2014; GREENWALD, 2014; MATTELART, 2009; SNOWDEN, 2019). Esse conjunto hegemônico de poderes econômico-políticos tem pouco, ou nenhum interesse, em apoiar e fomentar processos comunieducativos, que vigorizem e ampliem os conhecimentos necessários para resolver os problemas estruturais das formações sociais latino-americanas (DOWBOR, 2018, 2020; FURTADO, 2007, 2009; IANNI, 2000; SANTOS, 2002).

A pesquisa crítica em comunicação precisa produzir conhecimentos básicos, consistentes, que demonstrem os paradoxos, as contradições, os anacronismos, os absurdos, as incoerências e as injustiças que sustentam o modelo hegemônico, oligárquico/ plutocrático, que gera pobreza, miséria, atraso socioeconômico, racismo, violência, fragilidade educativa, e as carências científico/técnicas na região. Nossa configuração epistemológica transdisciplinar demanda um diálogo constante com várias áreas do conhecimento (Sociais, Humanas, Biológicas, Físicas, Naturais, Artísticas); exige uma imbricação, com ênfases necessárias, para cada projeto de investigação; suscita arranjos e combinações experimentais importantes para descrever, interpretar, explicar, analisar, sistematizar e comunicar os conhecimentos. De fato, nossa configuração como campo de conhecimento multidimensional torna improdutivo, repetitivo, redutor, enfraquecedor um exercício esquemático dos processos investigativos. Os pontos de partida, os lugares de pensamento, as premissas, as intuições, o movimento, as dinâmicas, as configurações instáveis, os processos e a existência comunicativa orientam as pesquisas estratégicas para desenhos e formulações transmetodológicas.

A potência epistemológica da transmetodologia ao estabelecer a necessidade lógica/ investigativa da confluência e confrontação de métodos (MALDONADO, 2013, 2015, 2019a); ao definir a obrigação de gerar estratégias, desenhos e táticas metodológicas, em sintonia com as problemáticas concretas (MARX, 1977; GORTARI, 1956, 1980; MATTELART; MATTELART, 2004; MATTELART, 2009; MATTELART; SÉNÉCAL, 2014; MATTELART; VITALIS, 2015; HARVEY, 2005, 2014); ao exigir a problematização (desmontagem e reconstrução) dos métodos pertinentes para cada pesquisa; ao demandar a produção de uma concepção metodológica própria para cada sujeita/sujeito científica/ científico, que formula uma investigação; ao arquitetar um conjunto de fases investigativas necessárias, que incluem a investigação-da-investigação, a investigação-exploratória, a investigação teórica, a investigação metodológica e a investigação tecnológica; estabelece parâmetros lógicos indispensáveis para a produção de conhecimento crítico relevante (MALDONADO, 2013, 2016, 2018, 2019a; BONIN, 2011; BONIN; ROSÁRIO, 2013).

\section{Os impasses das democracias liberais restritas, e a urgência da construção de poderes comunieducativos para a transformação}

Os enquadramentos neoliberais no Brasil, na América Latina (DOWBOR, 2018, 2020; PIKETTY, 2014, 2015) e no mundo, condicionam de modo estrutural a vida, a existência, o 
funcionamento, os processos de produção, as relações de trabalho, os benefícios, as exclusões, os limites, as possibilidades de criação e os modos de comunicação social. A lógica do capital cognitivo/informacional/financeiro sistematiza, e articula, o conjunto dos processos econômico/políticos e sociais das formações estruturais, que funcionam em nível mundial. De fato, tem-se uma diversidade de configurações em termos econômicos capitalistas, a de maior sucesso, sem dúvida é a chinesa (DOWBOR, 2018), que tem estruturado um capitalismo de Estado com responsabilidade social e visão estratégica de potência mundial em ascensão. Com efeito, os estrategistas chineses desenharam uma série de processos e estratégias que combinam modos capitalistas de funcionamento (keynesiano, fordista, liberal, flexível, cognitivo, informacional) com planejamento, controle, centralização/descentralização, regiões autônomas, eficiência administrativa, agilidade, avaliação e enquadramento da economia nos termos do Partido Comunista Chinês. Esse processo, durante os últimos 45 anos, tem sido paradigmático no mundo; já que a diferença das ortodoxias de Europa oriental, entre as décadas de 1930 e 1980, os estrategistas chineses definiram muito bem sua linha explicita de capitalismo de Estado para construir as bases tecnológicas, econômicas, produtivas e socioculturais de transformações estratégicas vigorosas ${ }^{2}$.

Em sentido contrário, o modelo capitalista neoliberal de democracias restritas (lobbies, oligarquias, plutocracias, holdings e complexos transnacionais), em especial o hegemônico estadunidense, no último meio século, tem dado continuidade a estratégias de agressão, invasão, violência, golpes de Estado (CHOMSKY, 2004), redução constante dos direitos trabalhistas e desenhos de superconcentração de renda na plutocracia transnacional. A ilusão de estabelecer um Estado Mínimo, proposta em finais dos anos 1970, caiu estrondosamente com as crises reais periódicas do capitalismo, em especial a que se iniciou em 2008, cuja lógica autodestrutiva continua a operar, como muito bem o demonstrou cientificamente Karl Marx no século XIX, e atualmente o ilustram Harvey (2005, 2014), Piketty (2014, 2015) e Dowbor (2020), de maneira decisiva. O problema crucial é que hoje em dia o capital improdutivo (financeiro, especulativo) (DOWBOR, 2018) é o núcleo central das formações econômicas articuladas e dependentes do poder transnacional estadunidense, que executa uma ação sistêmica de destruição de setores produtivos importantes (DOWBOR, 2020).

Na conjuntura atual a convergência sistêmica entre capital improdutivo e complexo militar/informacional/industrial é nefasta para o conjunto da humanidade. Afeta a cidadãos estadunidenses, a cidadãos da União Europeia; como também afeta, em maior intensidade, a cidadãos latino-americanos, africanos e asiáticos. Os milhões de seres humanos que são vítimas da fome, da miséria, dos vírus, da poluição, das doenças também são vítimas desse modelo, que concentra recursos nas áreas financeira, militar, informacional (de controle e vigilância), e do luxo (mansões, jatos, iates, joias). Simultaneamente, esse mesmo modelo

2 Dos mil milhões de pessoas que saíram da pobreza nas últimas décadas, 700 milhões são chineses (DOWBOR, 2018). 
nega recursos para as áreas da saúde, da educação, da ciência, da cultura, dos serviços sociais, da ecologia, do transporte social, da tecnologia cidadã e do viver pleno.

Na complexidade do real sócio-histórico existem diferenças entre as políticas de vários Estados da Organização para a Cooperação e Desenvolvimento (OCDE), e de grupos democráticos ao interior desses países. Porém, lamentavelmente, as ações sistêmicas preponderantes vão no sentido de aumento intensivo das desigualdades sociais, de intensificação dos conflitos, de negação da diversidade cultural, de confrontação com formações sociais que seguem modelos diferentes ao hegemônico. Aos povos que defendem sua soberania e dignidade se agride com militarismo, Lawfare (advocacia de guerra), racismo e neocolonialismo (disfarçado de modernidade e democracia). A estratégia de Lawfare, aplicada sistematicamente nesta última década na América Latina, tem sido eficiente e devastadora para enfraquecer, ainda mais, as frágeis democracias da região. A Lawfare gerou a criminalização de movimentos sociais, de grupos étnicos, de ativistas ecológicos, de pensadoras(es), de investigadoras(es), de jornalistas, de dirigentes políticos democráticos, de movimentos sociocomunicacionais, de manifestações culturais e de movimentos de gênero. Assim, a Afare comprova o redesenho das estratégias de dominação imperiais na América Latina.

Em concreto, temos estratégias de extermínio para grupos étnicos, em especial os povos originários e os afro-americanos; estratégias de destruição destinadas a populações críticas da hegemonia; como também, agressões cotidianas a setores sociais marginalizados, a militantes democráticos, a setores LGBTQI+, a ativistas ecológicos, a religiosas(os), a pobres e classes subalternas. Essa estratégia de extermínio, é combinada com estratégias jurídicas de Lawfare para desmontar e fragmentar os poderes políticos alternativos, os movimentos sociais, a cidadania ativa/crítica/construtiva, e os regimes constitucionais (MALDONADO, 2016).

Em termos econômicos estruturais, esse conjunto de estratégias têm sido formuladas para garantir os interesses do capital improdutivo/especulativo/plutocrático/informacional, no seu processo devastador de concentração de renda, e de fabricação de pobreza, miséria, violência, doenças e desemprego. Assim, o arranjo plutocrático/burocrático estabelece e mantem as estruturas de desigualdade, injustiça, desemprego, marginalização, privilégios, concentração de renda, violência sistêmica e gestão ineficiente dos governos locais e federais. Todos esses arranjos estão ao serviço de um poder plutocrático, transnacional e hegemônico, que impede e dificulta o trabalho científico, enfraquece os processos educativos, e reduz as práticas comunicacionais aos formatos, algoritmos e modos neoliberais (MATTELART; VITALIS, 2015; DOWBOR, 2018, 2020).

Nesse contexto globalitário, a vertente transmetodológica propõe a urgência da construção de poderes comunieducativos para a transformação sociocultural, política e econômica das sociedades latino-americanas. A construção desses poderes precisa da participação de pesquisadoras(es), pensadoras(es), cientistas, professoras(es), profissionais, técnicas(os), estudantes que desenhem, trabalhem e desenvolvam projetos comunieducativos estratégicos. 
A realidade contemporânea tem mostrado o potencial da comunieducação quando são desenhados planos, programas, projetos e organizações que sabem combinar métodos, táticas, procedimentos, estratégias e teorias, para construir e realizar processos comunieducativos, cidadãos, de abrangência latino-americana. Para ilustrar isso, estão, como experiências qualitativas paradigmáticas, a Tal.tv e o Canal Conecta, que se constituíram como projetos macroestruturais fecundos. Entretanto, a reação conservadora e neofacista, na segunda década do século XXI na região, indica que é necessário combinar projetos (micro e macro); e que as relações entre eles precisam ser de autonomia/cooperação, não de dependência.

O processo histórico das duas primeiras décadas do século XXI, na América Latina, tem comprovado o imenso potencial comunieducativos de projetos formulados e realizados por núcleos e grupos universitários, como tem sido o caso do Núcleo de Comunicação \& Educação, da USP, em parceria com o governo municipal dessa megalópole. Com efeito, os benefícios obtidos para a educação integral de adolescentes e professores da rede pública têm sido expressivos para a existência de um campo democrático em contextos de resistência, pela realização de processos de cidadania comunicativa, a partir do espaço escolar (ROMANCINI; ALVES; SOARES, 2012; ROMANCINI; CASTILHO, 2017; ROMANCINI, 2018).

Na mesma linha comunieducativa temos o referente do Centro de Experimentação para a Aprendizagem Permanente (CEPAP), na Venezuela, que tem suscitado uma cultura educomunicativa relevante, em amplos setores populares desse país; ao definir estratégias de inter-relação entre comunidades e universidade, que quebram a lógica neocolonial das academias "ocidentalizadas", e estabelece vínculos fortes, profundos e afetivos com as populações de trabalhadoras e trabalhadores dos bairros populares, comunas, assentamentos, aldeias e setores pouco favorecidos da sociedade venezuelana. Esse processo de abertura da universidade e de democratização da educação, combinando métodos educomunicativos de trabalho, tem possibilitado o ingresso de dezenas de milhares de estudantes das classes subalternas na Universidade Nacional Experimental Simón Rodríguez (UNESR). O núcleo central dessa articulação tem sido o Método de Projeto CEPAP; que, em termos transmetodológicos, reúne uma concepção transformadora que imbrica saberes ancestrais, étnicos, populares, e de grupos; com saberes científico/acadêmicos críticos. O Método de Projeto CEPAP em confluência com a transmetodologia situa a produção de conhecimento, em perspectiva heurística, em cada sujeita(o) estudante, como pensadoras(es) protagonistas que escrevem sua história para expressar seus talentos, capacidades, conhecimentos, particularidades e distinções.

Desse modo, o CEPAP-UNERS desenvolve estratégias transmetodológicas que aglutinam práticas teóricas e empíricas em experiências de reflexão, avaliação, crítica, redesenho e execução, mediante exercícios epistemológicos que dialogam com orientações transmetodológicas, no sentido da prioridade da espécie humana, da vida, das espécies, da natureza, da produção de conhecimento em sintonia ecológica com a biosfera. Concomitantemente, o Método de Projeto CEPAP expressa seu vigor transmetodológico na imbricação de uma dimensão ética/política com a dimensão acadêmica que problematiza 
as realidades, as existências, as transformações, os processos, as estruturas e os projetos de mudança; e as constituem em um componente necessário do fazer acadêmico; e, assim, marca distância da pretensão de "purgação" da vida acadêmica que o positivismo propõe (VALDEZ, 2011, 2013; REYES, 2011; RODRÍGUEZ, 2010; LEÓN, 2011; PADILLA, 2010, ESPINAL, 2009).

O Método de Projeto CEPAP concretiza a premissa transmetodológica que argumenta a favor da incorporação da investigação, como práxis indispensável, de todo processo de aprendizagem (VALDEZ, 2011; PADILLA et al., 2009; PADILLA, 2010; RODRÍGUEZ, 2010; REYES, 2011; LEÓN, 2011). Essa premissa marca distância dos modelos e das práticas acadêmicas especulativas, retóricas, burocráticas, formalistas, elitistas, utilitaristas, neocoloniais e neoliberais ao inserir a pesquisa como eixo necessário dos processos pedagógicos. Simultaneamente, coloca a investigação como uma necessidade e um direito de toda(o) estudante; questiona o senso comum acadêmico, que reduz a existência universitária à repetição de fórmulas e de receitas produzidas nos Estados Unidos da América (EUA), e nos centros de poder de conhecimento do hemisfério norte. Assim como degrada a atividade educativa ao consumo de slogans marketeiros, de moda, em especial aquele que restringe o trabalho educativo à lógica da mercadoria. O CEPAP questiona, também, os modelos retóricos, doutrinais e verticais, que negam a potência investigativa das(os) estudantes das classes subalternas, das etnias marginalizadas, das mulheres e dos grupos de gênero, considerados tabu pela moralidade inquisitorial conservadora e neofascista.

Os processos anteriores são significativos de um conjunto de experiências comunieducativas em realização na América Latina, que permitem projetar ações sistemáticas de fortalecimento das metodologias transformadoras, produzidas nesses movimentos sociocomunicacionais. Nessa perspectiva, a investigação histórica desses projetos e processos é imprescindível para constituir fortalezas de conhecimento estratégico na região. As orientações transmetodológicas propõem a formulação de investigações exploratórias para situar, registrar e sistematizar experiências que são cruciais em uma primeira fase das pesquisas; a continuação indica para a realização de uma investigação-da-investigação abrangente, que condense o conhecimento que já foi construído sobre a problemática e compartilhe esses saberes e conhecimentos com os núcleos em redes de cooperação, potencializando significativamente as condições de transformação comunieducativa necessárias para superar o neocolonialismo e o neofascismo vigentes. A vertente transmetodológica define, também, a necessidade em todo processo educativo/investigativo de formular/realizar uma investigação teórica, que gere hipóteses, conceitos, noções e argumentos enriquecedores da compreensão das problemáticas comunieducativas; nesse sentido, todas(os) somos produtoras(es) de teorias, pensadoras(es) vivas(os) (BACHELARD, 2006; SARTRE, 2011; MILLS, 1975; MALDONADO, 2016, 2018, 2019a).

Na mesma perspectiva multifacetada, impura e multilética, a transmetodologia indica a necessidade da realização de uma investigação metodológica em todo processo de ensino/aprendizagem; considera assim que não há métodos prontos, acabados, completos, 
simplesmente aplicáveis. Propõe a construção de metodologias, de estratégias, de táticas, de procedimentos e de técnicas, como um requisito necessário de todo trabalho educativo/ inventivo, por mais simples que este seja. Só a problematização comprometida, consciente, organizada e reconstrutiva dos métodos tornará uma investigação e um processo educativo em transformadores, e fortalecedores, de culturas investigativas e educativas solidárias, inventivas e ecológicas.

A Transmetodologia reúne um potencial epistemológico, teórico e metodológico, significativo para orientar esses processos; nutre-se das experiências e das sabedorias históricas seculares ameríndias, africanas, asiáticas e europeias. Alimenta-se dos conhecimentos críticos mundiais (WALLERSTEIN et al., 2001), gerados pelas comunidades de conhecimento de maior fecundidade na humanidade. Aprende com o movimento vital da natureza, do planeta e do cosmos nas suas dinâmicas de integralidade, de continua transformação, de inter-relação colaborativa, de confrontação frutífera, e de reconstrução necessária de mundos. Em uma conjuntura como a atual, de reação intensa de anacronismos políticos, ideológicos, religiosos e econômicos, a opção transmetodológica abre potencialidades suscitadoras para o trabalho político/investigativo de transformação de Nossa América.

\section{Referências}

ASSANGE, J. Cuando Google encontro a Wikileaks. Buenos Aires: Capital Intelectual, 2014.

BACHELARD, G. Epistemologia. Lisboa: Edições 70, 2006.

BONIN, J. Revisitando os bastidores da pesquisa: práticas metodológicas na construção de um projeto de investigação. In: MALDONADO, A. E. Metodologias de pesquisa em comunicação: olhares, trilhas e processos. Porto Alegre: Sulina, 2011. p. 19-42.

BONIN, J.; ROSÁRIO, N. (org.). Processualidades metodológicas: configurações transformadoras em comunicação. Florianópolis: Insular, 2013.

CHOMSKY, N. O império americano: hegemonia ou sobrevivência, 2004.

DOWBOR, L. A era do capital improdutivo. São Paulo: Outras Palavras \& Autonomia Literária, 2018.

DOWBOR, L. O capitalismo se desloca: novas arquiteturas sociais. São Paulo: Edições SESC, 2020.

ESPINAL, A. La Escuela para la participación en salud social: una experiencia de formación transdisciplinar. In: PADILlA, A.; MALDONADO, A. E. (org.). Metodologías transformadoras: Tejiendo la red en comunicación, educación, ciudadanía e integración en América Latina. Caracas: Fondo Editorial CEPAPUNESR, 2009. p. 201-219.

FURTADO, C. A economia latino-americana: formação histórica e problemas contemporâneos. 4. ed. São Paulo: Companhia das Letras, 2007.

FURTADO, C. Formação econômica do Brasil. São Paulo: Companhia das Letras, 2009.

GORTARI, E. Introducción a la lógica dialéctica. México: Fondo de Cultura Económica, 1956.

GORTARI, E. La ciencia en la historia de México. México: Grijalbo, 1980.

GREENWALD, G. Snowden: sin un lugar donde esconderse. Barcelona: Ediciones B.S.A, 2014. 
HARVEY, D. A produção capitalista do espaço. São Paulo: Anablume, 2005.

HARVEY, D. Guía de El Capital de Marx: Libro primero. Madrid: Akal, 2014.

IANNI, O. Enigmas da modernidade-mundo. Rio de Janeiro: Civilização Brasileira, 2000.

LEÓN, A. Historias de vida: un recorrido por lo transdisciplinario. In: MALDONADO, A. E. Metodologías transformadoras: tejiendo la Red en Comunicación, Educación, Ciudadanía e Integración en América Latina. Caracas: Red AMLAT-UNESR-CEPAP, 2011. p. 169-192.

MALDONADO, A. E. A perspectiva transmetodológica na conjuntura de mudança civilizadora em inícios do século XXI. In: MALDONADO, A. E. Perspectivas metodológicas em comunicação: novos desafios na prática investigativa. Salamanca: Comunicación Social Ediciones y Publicaciones, 2013. p. 31-57.

MALDONADO, A. E. Epistemología de la Comunicación: Análisis de la vertiente Mattelart en América Latina. Quito, Ecuador: CIESPAL, 2015.

MALDONADO, A. E. Transmetodología en tiempos de fascismo social. Chasqui. Revista Latinoamericana de Comunicación, Quito, n. 133, p. 211-227, 2016.

MALDONADO, A. E. Articulaciones transmetodológicas para una epistemología latinoamericana en comunicación. Revista ALAIC, São Paulo, v. 15, n. 28, p. 60-71, 2018.

MALDONADO, A. E. A perspectiva transmetodológica: produtos midiáticos, estratégias e inter-relações comunicativas. In: OLIVEIRA, G.; SANTOS, L.; BONITO, M. Comunicação em Contextos de Pesquisa. Assis/SP: Triunfal-UNIPAMPA, 2019a. p. 183-212.

MALDONADO, A. E. El desafío epistemológico de la praxis teórica en la construcción de teorías de la comunicación. Mediaciones Sociales, Madrid, v. 18, p. 11-24, 2019b.

MALDONADO, A. E. et al (org.). Epistemologia, investigação e formação científica em comunicação. Rio do Sul-Natal: EUNIDAVI-EUFRN, 2012.

MALDONADO, A. E.; BARRETO, V. S.; LACERDA, J. S. (org.). Comunicação, educação e cidadania: saberes e vivências em teorias e pesquisa na América Latina. João Pessoa; Natal: Editora da UFPB; Editora da UFRN, 2011.

MALDONADO, A. E.; PEREIRA, A. (coord.). Investigación de la comunicación en América Latina. Quito FACSO-UCE, 2010.

MARX, K. Contribuições para a crítica da economia política. Lisboa: Estampa, 1977.

MATTELART, A. Un mundo vigilado. Barcelona: Paidós, 2009.

MATTELART, A.; MATTELART, M. Pensar as mídias. São Paulo: Loyola, 2004.

MATTELART, A.; SÉNÉCAL, M. Por una mirada-mundo: conversaciones con Michel Sénécal. Barcelona. GEDISA, 2014.

MATTELART, A.; VITALIS, A. De Orwell al Cibercontrol. Barcelona: Gedisa, 2015.

MILLS, C. W. A imaginação sociológica. 4. ed. Rio de Janeiro: Zahar, 1975.

PADILLA, A. Descentramiento de la educación en tiempos de nuevas pantallas. In: PEREIRA, A.; MALDONADO, A. E. (coord.). Investigación de la comunicación en América Latina. Quito: Fondo Editorial FACSO-UCE, 2010. p. 241- 257.

PADILLA, A. et al. Reinventemos la educación para libertar(nos): aprendizajes, investigación, conocimientos y acción transformadora. In: PADILLA, A.; MALDONADO, A. E. (org.) Metodologías transformadoras: 
Tejiendo la red en comunicación, educación, ciudadanía e integración en América Latina. Caracas: Fondo Editorial CEPAP-UNESR, 2009. p. 221- 255.

PADILlA, A.; MALDONADO, A. E. (org.). Metodologías transformadoras: Tejiendo la red en comunicación, educación, ciudadanía e integración en América Latina. Caracas: Fondo Editorial CEPAPUNESR, 2009.

PADILlA. A.; MALDONADO, A. E.; GAMBOA, N. S. (org.) Procesos comunicacionales, educación y ciudadanía en las luchas de los pueblos. Caracas: Fondo Editorial CEPAP-UNESR, 2015.

PIKETTY, T. O capital no século XXI. Rio de Janeiro: Intrínseca, 2014.

PIKETTY, T. A economia da desigualdade. Rio de Janeiro: Intrínseca, 2015.

REYES, A. La metáfora: una vía para el cultivo del conocimiento y los saberes en los procesos de aprendizaje. In: MALDONADO, A. E; BARRETO, C. V.; LACERDA, J. (org.). Comunicação, educação e cidadania: saberes e vivencias em teorias e pesquisa na América Latina. Natal/João Pessoa: EUFRNEUFPB, 2011. p. 48-70.

RIFIOTIS, T. et al. Redes sociotécnicas: hibridismos e multiplicidade de agências na pesquisa de Cibercultura. In: MALDONADO, A. E; BARRETO, V.; LACERDA, J. (org.). Comunicação, educação e cidadania: saberes e vivências em teorias e pesquisa na América Latina. Natal/João Pessoa: EUFRNEUFPB, 2011, p. 221- 245.

RODRÍGUEZ, O. La audiencia soñada como una propuesta política educomunicativa y popular de visión crítica del cine. In: MALDONADO, A. E; PEREIRA, A. (coord.). Investigación de la comunicación en América Latina. Quito: FCS-UCE-Rede AMLAT, 2010. p. 199-240.

ROMANCINI, R. Do “Kit Gay” ao “Monitor da Doutrinação”: a reação conservadora no Brasil. Contracampo, Niterói, v. 37, n. 2, p. 1-22, 2018.

ROMANCINI, R.; ALVES, P. H.; SOARES, M. S. P. Pesquisa em mídias na educação: parâmetros de qualidade para o trabalho do professor pesquisador. Recife: Gráfica e Editora Liceu, 2012.

ROMANCINI, Richard; CASTILHO, F. Novos letramentos e ativismo: aprendizagens formal e informal nas ocupações de escolas em São Paulo. Revista ALAIC, São Paulo, v. 14, n. 26, p. 128-138, 2017.

SANTOS, M. A natureza do espaço, técnica e tempo, razão e emoção. São Paulo: EDUSP, 2002.

SARTRE, J. P. Crítica de la razón dialéctica: teoría de los conjuntos prácticos. Buenos Aires: Losada, 2011. SNOWDEN, E. A eterna vigilância: como montei e desvendei o maior sistema de espionagem do mundo. São Paulo: Planeta do Brasil, 2019.

VALDEZ, J. C. Andragogia y educación popular: um diálogo inminente. In: MALDONADO, A. E; BARRETO, C. V.; LACERDA, J. (org.). Comunicação, educação e cidadania: saberes e vivencias em teorias e pesquisa na América Latina. Natal/João Pessoa: EUFRN-EUFPB, 2011. p. 91-112.

VALDEZ, J. Movimientos sociales en Venezuela: una propuesta transformadora. Caracas: Fundación editorial El perro y la rana, 2013.

WALLERSTEIN, I. et al. Abrir las ciencias sociales: informe de la comisión Gulbenkian para la reestructuración de las ciencias sociales. 5. ed. México: Siglo Veintiuno, 2001. 


\begin{abstract}
Alberto Efendy Maldonado
É pós-doutor pela Universidade de Barcelona (2004-2005). Trabalha desde 1999 no PPGCCUNISINOS, Porto Alegre, Brasil, é Professor Titular (Catedrático)/Pesquisador. Orienta e supervisiona investigações de doutorado (prêmios CAPES - 2011 e COMPÓS - 2019, orientação), mestrado, iniciação científica e pós-doutorado. É Catedrático Titular da cátedra Armand Mattelart do CIESPAL; coordenador geral para América Latina da Rede AMLAT. Coordenador Adjunto do GP-PROCESSOCOM-CNPq. Investigador Prometeu/SENESCYT e CNPQ/Produtividade. Autor de investigações e obras de referência de caráter epistemológico, teórico e metodológico na América Latina. E-mail: efendymaldonado@gmail.com.
\end{abstract}

Recebido em: 10.10 .2020

Aprovado em: 30.08.2021 